\title{
Bridge deck condition assessment by using GPR: a review
}

\author{
Tahar Bachiri, ${ }^{1, a}$, Abdellatif Khamlichi ${ }^{2}$ and Mohammed Bezzazi ${ }^{1}$ \\ ${ }^{1}$ Department of Physics, Faculty of Sciences and Technology at Tangier, University Abdelmalek Essaadi, Tangier 93001, Morocco \\ ${ }^{2}$ Department STIC, National School of Applied Sciences at Tetouan, University Abdelmalek Essaadi, Tetouan 93030, Morocco
}

\begin{abstract}
Bridge deck deterioration includes delamination, corrosion of rebars, vertical cracking and concrete degradation. Ground Penetrating Radar based inspection technique was used for mapping bridge deck in order to monitor the health of this vital structure. Beginning from the 1970's, research has focused on identification of bridge deck deterioration which causes severe deficiencies by reducing seriously strength. The main purpose of this work was to review the literature existing in the field of bridge deck diagnosis by means of Ground Penetrating Radar. This enabled to survey detailed evolution of this technique, to understand the effects of key intervening parameters and to determine the kind of material disorders that this device could be used for. Bridge deck condition assessment can then be performed more successfully, based on the huge progress experienced by this particular method of inspection.
\end{abstract}

\section{Introduction}

Bridges are vital infrastructures for transportation activity. They require recurring maintenance and repair which can result expensive. Setting up more efficient and cost-effective methods for monitoring conditions of bridge decks is viewed to be highly imperative.

According to statistics about a quarter of constructed bridges are deficient due to stringent structural disorders or because they are functionally out of date. It was documented that the most important cause of deficiency in concrete bridge structures is corrosion of steel reinforcements [1]. The main other causes of bridge condition shortage include delamination, concrete carbonation, scaling and spalling. Delamination in concrete occurs when reinforcements corrode to the point that they expand, creating a horizontal crack.

Most corrosion processes are induced by the presence of chloride due to water and salt infiltration. Corrosion induced deteriorations need several years to rise and to become visible on the surface of the structure. The ability to perform diagnosis of bridge deck problems at their early stage can increase their service life and diminish reparation costs. Conventional inspection techniques of bridge deck consist of methods such as hammer sounding, ultrasonic pulse propagation velocity as well as infrared thermography. Recently, Ground penetrating Radar (GPR) has emerged as an outstanding technology which is both expedient and reliable for operating non-destructive bridge deck assessment. GPR is an electromagnetic investigation method which is nondestructive and fast. It can also be contact-less by using air-coupling mode. GPR can be used either in reflection

a Corresponding author: Bachiri.Tahar69@,hotmail.com or transmission mode, but reflection methods are the most frequent. GPR was recognised to be well suited for the detection of delamination and corrosion of rebars [2]. The common method used for the assessment of bridge deck condition is based on the attenuation of the reflected waves. A close relationship exists between the GPR reflection amplitudes and the chloride content in concrete and the higher the chloride content is, the lower the signal amplitudes are [3-4].

Feasibility of GPR in detecting delamination damage has received vast interest. In a comparative study conducted by Barnes and Trottier [5], GPR was found to provide better results, with up to $57 \%$ of deteriorated concrete cases detected. In another study GPR was able to identify $77 \%$ of the deteriorated areas and the depth of cracking was measured with accuracy reaching $80 \%$ [6]. Other research presented a correlation between GPR amplitudes and corrosion induced delamination [7]. It should be noticed that while delamination causes usually an attenuated GPR response, the reverse is not always true. Weak amplitudes may indicate delamination but also variations in moisture content or surface distresses. The variety of physical and environmental factors that may dampen the GPR response has been detailed in [8].

\section{GPR theory and principles}

In reflection mode, the principle of GPR consists of emitting an electromagnetic pulse via a transmitter antenna. This pulse propagates before undergoing reflections at the surface or interior layer boundaries of an object. The echo signal is recorded via the receiver antenna. The result of a single GPR measurement with 
the device placed at a given position is a time-series, called A-scan. This curve is characterised by amplitude and two-way-travel time of the reflected signal. The twoway-travel time or time of flight is the time required to propagate to a reflector and back to the receiver.

In an homogenous and isotropic dielectric medium, the velocity of electromagnetic waves is constant velocity and depends on the relative permittivity $\varepsilon_{r}$ and the relative permeability $\mu_{r}$. For materials fit for the radar method, $\mu_{r}=1$ is assumed and the wave speed within a material is defined by the relative permittivity. This assumption is of course not valid for ferromagnetic materials, but using GPR for these materials is unsound. For ordinary materials the relative permittivity varies from $\varepsilon_{r}=1$ (for air) to $\varepsilon_{r}=84$ (for water), then electromagnetic wave velocity varies between $v=0.11 \mathrm{c}$ (for water) and $v=c$ (for air) where $c$ is the velocity in vacuum. The wave velocity is high, which is useful to get a high number of measurements per second.

The GPR device works by transmitting an electromagnetic energy pulse of short duration into the surface and recording reflections that occur at interfaces of materials having different dielectric properties. The reflected echoes can be monitored by focusing on reflected wave amplitude, arrival time, distortion of source wave or energy attenuation [9]. When hitting an interface, part of the energy of an electromagnetic wave is transmitted, while the other part is reflected. For a plane electromagnetic wave in a low-loss material, under vertical incidence, hitting an interface between two materials with the incident and transmitted relative primitives $\varepsilon_{r 1}$ and $\varepsilon_{r 2}$, the reflected wave amplitude is characterized by the reflection coefficient

$$
R=\frac{\sqrt{\varepsilon_{r 1}}-\sqrt{\varepsilon_{r 2}}}{\sqrt{\varepsilon_{r 1}}+\sqrt{\varepsilon_{r 2}}}
$$

The two-way-travel time is given by

$$
T O F=\frac{2 d}{v}
$$

where $d$ is the thickness of the incident layer. Knowing the value of TOF can be used to determine the thickness, when the velocity $v$ is identified.

The ability of the GPR method to separate single objects (lateral resolution) is limited by the size of the Fresnel region which is the area where reflected waves interfere constructively. Two points within this area cannot be distinguished by the radar signal. In general, lateral resolution increases with the work frequency $f$ and decreases with the target depth $d$. The depth of wave penetration depends on the conductivity of the medium and the work frequency. Increasing the frequency of waves reduces the depth of penetration.

GPR data can be acquired and presented in various modes. Moving the antenna along a horizontal line, GPR measurements can be recorded at close intervals. The recorded time-series can be plotted side by side with the time axis pointing downwards and the horizontal axis corresponding to the line along which the antenna is moved. This display provides a B-scan.

The frequency content of the emitted and recorded radar signal is mainly defined by the antenna configuration. The choice of the appropriate antenna is important. Currently, antenna with centre frequencies between some $\mathrm{MHz}$ (low resolution and high depth of penetration) and some $\mathrm{GHz}$ (high resolution and low depth of penetration) are available.

There are several limitations restricting the use of radar and the accuracy of results. A sufficient contrast in material properties is required to enable investigation of the interface between two materials. Without such contrast the boundary will not appear in the radar raw data. This is why GPR can detect corrosion-induced delamination, but not cracking due to traffic overloading which is not visible on radargram.

\section{Review of the GPR literature related to bridge deck condition assessment}

The history of GPR tests in surveying bridge deck condition dates back to the 1970's [10]. In the early 1980's, GPR based bridge inspections have expanded [11-14]. The first vehicle mounted GPR system for high-ways was developed in 1985 [15]. The obtained results were really promising and the method rapidly became a routine survey tool in various rehabilitation projects of roads and bridges [16-17].

In the late 1980's and early 1990's, most of applications of GPR that were dedicated to detection of deteriorated areas in bridge decks [18-27]. These surveys were mainly conducted with high frequency $1 \mathrm{GHz}$ air-coupled antennas [28]. But later, ground coupled antennas were also used [29]. In the late 1990's and early 2000's, research in the field of bridge inspection focused on detection of river-bed scour around bridge piers by means of boat-mounted impulse radar survey equipment [30-32], detection of voids in post tensioned concrete bridge beams [33], mapping concrete deterioration [3435], new antenna designed for bridge deck evaluation [37] and accuracy and reliability of GPR [5,38-39]. GPR has been well recognized as an effective and efficient technology for bridge deck inspection [40-41]. In the following, a review of the most important literature published this last decade on bridge deck deterioration assessment is performed. Maser et al. [42] considered the relationship between GPR measurements and the state of deck deterioration in order to classify stages of the deterioration process. Mercedes et al. [43] investigated the uncertainty evaluation in the measurement provided by GPR for operating frequencies of $1 \mathrm{GHz}$ and concluded that important differences may be related to operators. Benedetto [44] proposed a novel numerical approach for three dimensional tracking and mapping of cracks in a bridge deck. He tested the numerical approach on data acquired by using $2 \mathrm{GHz}$ GPR system. Alani et al. [45] conducted an experimental study on two major British bridges for identifying possible structural defects. They showed that remarkable 
similarity exists in the processed data concerning areas affected by ingress of moisture within the two bridges deck structures. The authors concluded that interpretation of GPR can take profit from lessons learned in earlier investigations.

Gucunski et al. [46] concentrated on bridge deck condition assessment using various non-destructive evaluation (NDE) techniques. They demonstrated the ability of NDE methods to objectively characterize deterioration progression. Dinh et al. [47] analyzed several depth correction approaches proposed to account for variation of concrete cover thickness on the rebar reflection amplitude of the GPR signal. They proposed separating normalization of the depth-dependent amplitudes into two components which was shown to significantly improve the accuracy.

Post-processing of GPR acquired data was the centre of several works. The research focused mainly on automating the process of interpretation and processing of GPR records. Dinh et al. [48] focused on how to obtain the condition map for a concrete bridge deck through the relative difference between reflection amplitudes at the top rebar layer. The authors proposed and validated in this context a new method. In another work, Dinh et al. [49] have considered attenuation of GPR signal as reflected from the top rebar mat. They presented an alternative method for performing the GPR attenuation analysis in which correlations derived from waveforms with only one reflection were employed. The method was validated and achieved better description of the overall deterioration of bridge decks.

Abouhamad et al. [50] have considered detection of corrosion based on GPR signal attenuation and developed a systematic framework of image-based analysis of bridge deck. They validated the proposed methodology and concluded that their approach can be used in a more informed decision making process through highlighting areas of actual deterioration. Shakibabarough et al. [51] have focused on the interpretation of GPR image of bridge decks and proposed a novel algorithm for detecting areas of deterioration in rebar mat signatures. The proposed algorithm was validated on many real GPR images.

More recently Dinh et al. [52] presented an automated rebar picking algorithm for GPR data of concrete bridge decks. The algorithm is based on the limited and simplified hyperbolic summation technique. The picking algorithm provided good results with accuracy beyond 98\%. Dinh et al. [53] presented also an automated rebar localization and detection algorithm for performing picking of rebars based on conventional image processing techniques and deep convolutional neural networks. The process enabled to recognize and retain likely true rebar peaks and to discard likely false positive detections as the tests from twenty-six bridge decks showed an overall accuracy greater than $99 \%$.

\section{References}

1. A.A. Sohanghpurwala, Manual on Service Life of Corrosion-Damaged Reinforced Concrete Bridge
Superstructure Elements (Transportation Research Board, Washington, 2006)

2. N. Gucunski, A. Imani, F. Romero, S. Nazarian, D. Yuan, H. Wiggenhauser, P. Shokouhi, A. Taffe., D. Kutrubes, The Second Strategic Highway Research Program, Nondestructive Testing to Identify Concrete Bridge Deck Deterioration (SHRP 2 Report, Library of Congress, Washington, USA, 2013)

3. J. Hugenschmidt, R. Loser, Materials and Structures 41, 4 (2007)

4. A. Kalogeropoulos, Non-Destructive Determination of Chloride and Water Content in Concrete Using Ground Penetrating Radar ( $\mathrm{PhD}$ Thesis, Ecole Polytechnique Federale de Lausanne, Switzerland, 2012)

5. C.L. Barnes, J.F. Trottier, ASCE Journal of Infrastructure Systems 10, 2 (2004)

6. S. Yehia, O. Abudayyeh, I. Abdel-Qader, A. Zalt, Journal of the Transportation Research Board, 2044 (2008).

7. B.M. Pailes, N. Gucunski, M.C. Brown, Correlation of non-destructive testing results to improve assessment of corrosion and corrosion damage of a reinforced concrete deck (In Transportation Research Board 92nd Annual Meeting, Washington, USA, 2013)

8. C.L. Barnes, J. Trottier, Journal of the Transportation Research Board, 1795 (2002)

9. S. Cardimona, B. Willeford, J. Wenzlick, N. Anderson, Bridge Decks Condition Studies in Missouri Utilizing Ground Penetrating Radar: RDT 01-012 (Jefferson City, USA, 2001)

10. T.R. Cantor T, C. Kneeter, C (1978) Radar and Acoustic Emission Applied to Study of Bridge Deck, Suspension Cables and Masonry Tunnel (Transportation Research Record, Washington, USA, 1978)

11. T.R. Cantor, C.P. Kneeter, Radars as Applied to Evaluation of Bridge Decks. (Transportation Research Record, Washington, USA, 1982)

12. C.P.F. Ulriksen, Application of Impulse Radar to Civil Engineering (PhD Thesis, Lund University of Technology, Sweden, 1982)

13. G. Clemena, Nondestructive Inspection of Overlaid Bridge Decks with Ground Penetrating Radar (Transportation Research Record, Washington, USA, 1983)

14. D.G. Manning, F.B. Holt, Detecting Deterioration in Asphalt Covered Bridge Decks (Transportation Research Record, Washington, USA, 1983)

15. Morey R (1998) Ground Penetrating Radar for Evaluating Subsurface Conditions for Transportation Facilities (Transportation Research Board, Washington, USA, 1998)

16. T. Saarenketo, Geological Survey of Finland, $\mathbf{1 5}$ (1992) 
17. C.R. Carter, T. Chung, T. Masliwec, D.G. Manning, Geological Survey of Canada, 90 (1992)

18. K.R. Maser, W.M.K. Roddis, Journal of Transportation Engineering 116, 5 (1990)

19. N. Parry, J.L. Davis, Geological Survey of Finland, 16 (1992)

20. G.J. Weil, Geological Survey of Finland, 16 (1992)

21. T. Alongi, G.G. Clemena, P.D. Cady, Condition Evaluation of Concrete Bridges Relative to Reinforcement Corrosion, (SHRP Report, Washington, USA, 1992)

22. C.R. Carter, T. Chung, T. Masliwec, D.G. Manning, Geological Survey of Canada 90, 4 (1992)

23. F.P. Haeni, G. Placzek, R.E. Trent, Geological Survey of Finland, 16 (1992)

24. T. Saarenketo, M.K. Söderqvist, GPR Applications for Bridge Deck Evaluations in Finland (Proceeding of the Non-Destructive Testing in Civil Engineering, The University of Liverpool, UK, 1993)

25. P. Maijala, T. Saarenketo, P.Valtanen, Correlation of Some Parameters in GPR Measurement Data with Quality Properties of Pavements and Concrete Bridge Decks (Proceedings of the Fifth International Conference on Ground Penetrating Radar, Kitchener, Canada, 1994)

26. S.G. Azevedo, J.E. Mast, S.D. Nelson, E.T. Rosenbury, H.E. Jones, T.E. McEwan, D.J. Mullenhof, R.E. Hugenberger, R.D. Stever, J.P. Warhus, M.G. Wieting, SPIE, 2946 (1996)

27. D.E. Mesher, C.B. Dawley, P.C. Pulles, A Comprehensive Radar Hardware, Interpretation Software and Survey Methodology Paradigm for Bridges Deck Assessment (Proceedings of the Sixth International Conference on Ground Penetrating Radar, Sendai, Japan, 1996)

28. T. Scullion, C.L. Lau, Y. Chen, Implementation of the Texas Ground Penetrating Radar System, (Report of TDT, Texas, USA, 1992)

29. T. Scullion, S. Servos, J. Ragsdale, T. Saarenketo, Applications of Ground-Coupled GPR to Pavement Evaluation (Report of TDT, Texas, USA, 1997)

30. S.G. Millard, J.H. Bungey, C. Thomas, M.N. Soutsos, M.R. Shaw, A. Patterson, NDT \& E International 31, 4 (1998)

31. M.C. Forde, D.M. McCann, M.R. Clark, K.J. Broughton, P.J. Fenning, A. Brown, NDT\&E International, 32 (1999)

32. P. Inchan, L. Joengwoo, C. Woncheol, Assessment of Bridge Scour and Riverbed Variation by a Ground Penetrating Radar. (The 10th International Conference on Ground Penetrating Radar, Delft, The Netherlands, 2004)

33. A. Giannopoulos, P. MacIntyre, S. Rodgers, M.C. Forde, SPIE 4758 (2002).

34. N.C. Davidson, S.B. Chase, Radar Systems for Topographic Bridge Deck Inspection (Proceeding of the Seventh International Conference on Ground Penetrating Radar, Lawrence, USA, 1998)

35. F.A. Romero, R.L. Roberts, Mapping Concrete Deterioration: High Speed Ground Penetrating Radar Surveys on Bridge Decks Using New Analysis Method Based on Dual Polarization Deployment of Horn Antennae (International Bridge Conference, Pittsburgh, USA, 2002).

36. D. Huston, P. Fuhr, K. Maser, W. Weedon, Nondestructive Testing of Reinforced Concrete Bridges Using Radar Imaging Techniques (Report of The New England Transportation Consortium, New England, USA, 2002).

37. S. Cardimona, B. Willeford, J. Wenzlick, N. Anderson, Investigation of Bridgedecks Utilizing Ground Penetrating Radar, (ICAGT, St. Louis, USA, 2000)

38. H. Shin, D. Grivas, Transportation Research Board, 22 (2003)

39. J. Hugenschmidt, Accuracy and Reliability of Radar Results on Bridge Decks (Proceedings of the 10th International Conference on Ground Penetrating Radar, Delft, The Netherlands, 2004)

40. C.L. Barnes, J.F. Trottier, D. Forgeron, NDT\&E International 41, 6 (2008)

41. A. Tarussov, M. Vandry, A. De La Haza, Construction and Building Materials, 38 (2013)

42. K. Maser, N. Martino, J. Doughty, R. Birken, The Transportation Research Board, 2313, (2012)

43. S. Mercedes, H. González-Jorge, H. Lorenzo, P. Arias, Measurement, 46 (2013)

44. A. Benedetto, Journal of Applied Geophysics, 97 (2013)

45. A.M. Alani, M. Aboutalebi, G. Kilic, Journal of Applied Geophysics 97 (2013)

46. N. Gucunski, B. Pailes, J. Kim, H. Azari, K. Dinh, ASCE Journal of Infrastructure Systems (2016)

47. K. Dinh, N. Gucunski, J. Kim, T. Duong, NDT\&E International, 83 (2016)

48. K. Dinh, T. Zayed, F. Romero, A. Tarussov, ASCE Journal of Bridge Engineering 20, 6 (2015)

49. K. Dinh, N. Gucunski, J. Kim, T.H. Duong, NDT\&E International, 92 (2017)

50. M. Abouhamad, T. Dawood, A. Jabri, M. Alsharqawi, T. Zayed, Automation in Construction, 80 (2017)

51. A. Shakibabarough, A. Bagchi, T. Zayad, Automated Detection of Areas of Deterioration in GPR Images for Bridge Condition Assessment (Fourth Conference on Smart Monitoring, Assessment and Rehabilitation of Civil Structures, Zürich, Switzerland, 2017)

52. K. Dinh, N. Gucunsk, T.H. Duong, NDT\&E International, 98 (2018)

53. K. Dinh, N. Gucunski, T.H. Duong, Automation in Construction, 89 (2018) 